\title{
Use of Nanoparticle Enhanced Phase Change Material for Cooling of Surface Acoustic Wave Sensor
}

\author{
Mohammad Yaghoub Abdollahzadeh Jamalabadi
}

check for updates

Citation: Abdollahzadeh Jamalabadi, M.Y. Use of Nanoparticle Enhanced Phase Change Material for Cooling of Surface Acoustic Wave Sensor. Fluids 2021, 6, 31. https://doi.org/10.3390/ fluids6010031

Received: 3 December 2020 Accepted: 17 December 2020 Published: 8 January 2021

Publisher's Note: MDPI stays neutral with regard to jurisdictional clai$\mathrm{ms}$ in published maps and institutional affiliations.

Copyright: (C) 2021 by the authors. Licensee MDPI, Basel, Switzerland. This article is an open access article distributed under the terms and conditions of the Creative Commons Attribution (CC BY) license (https:// creativecommons.org/licenses/by/ $4.0 /)$.
Ship Engineering Department, School of Mechanical Engineering, Chabahar Maritime University, Chabahar 99717-56499, Iran; my.abdollahzadeh@cmu.ac.ir or abdollahzadeh@dongguk.edu

\begin{abstract}
The use of resonators, filters, interdigital transducers (IDT) and stable sources in electronic industry is widespread today. One of the most used filters are the surface acoustic wave (SAW) type, which is mostly based on Rayleigh waves propagation on the surface. On the other hand, the use of Phase change materials (PCMs) is considered as a heat sink method in the field of thermal cooling of electronic circuits. Recent development in heat transfer is obtained by nanoparticle-enhanced PCM (NEPCM), which is a result of combining nanoparticles with PCMs. Increase of thermal conductivity of NEPCM in comparison with common PCM enhances the heat transfer rate. The aim of the current study is thermal management of SAW for the application of high frequency heating by phase change material. Melting of NEPCMs inside a rectangular cavity next to the SAW cell is used for the cooling purpose. Free convection heat transfer of a NEPCMs in an square cavity is modeled throughout the mass and momentum. Energy governing equations are solved by using the finite element method. Electrohydrodynamic (EHD) forces exist in natural convection heat transfer within the fluid part of the enclosure. The results also show that the NEPCM causes heat transfer improvement up to $10 \%$.
\end{abstract}

Keywords: surface acoustic waves; thermal design; microfluidic; heat removal; MEMS; nanofluids; magnetic nanoparticles; electrically conductive fluid flows

\section{Introduction}

A Rayleigh surface acoustic wave (SAW) device carries an electro-acoustic wave propagating at the piezoelectric surface. Rayleigh waves and Stoneley waves happen at interfaces. For a free surface, the surface waves are known as Rayleigh waves. The wave also could be Acousto-fluidics, as shown by Wang et al. [1] By aid of AlN/Si. The usage of SAW includes many applications, such as microfluidics [1], propulsion system [2], determining the crystallographic orientation and velocity measurements [3], phononic crystals [4], solar panels [5], etc. Kong et al. [2] show, by using acoustic radiation force, that one can produce a propulsion system. Based on the type of crystal structure of materials (such as hexagonal) or their specific properties (such as $\mathrm{ZnO}$ ) the SAW technology can be applied in smarter way [6] and precise tools [7]. The criterion for surface waves or Rayleigh waves is that the displacement decays exponentially with distance from the free surface. The performance of the surface acoustic mode of propagation depends on the variation material property as a function of band structure. The performance of the SAW is influenced by damping factor on surface acoustic wave propagation. In this section, we briefly explain the starting background and the originality (novelty) and relevancy of the study to the SAW designs.

The coupling between mechanical (Rayleigh waves with vertical shear component and a longitudinal component) and electrical part make the design procedure more complex [7-10]. As an example, removal of spoiling materials from surfaces could be considered as a complex procedure (see Figure 1). The complexity of surface acoustic wave fields used for microfluidics applications was analyzed by Weser et al. [6]. This complex coupling changes the velocity and amplitude of the acoustic wave, which can measure any connected 
mass and mechanical properties. Chan et al. [9] explain the application of surface acoustic waves in field of Water Research. Analytically the Rayleigh wave effects correspond to the contributions from certain poles in the integrands of the inversion integrals. The use of MHz-Order improve the greywater treatment. Hsu and Lin [10] present the SAW devices for Microparticle concentration and separation inside a droplet using phononic-crystal scattered standing SAW. A review on surface acoustic wave-based ultraviolet photodetectors was done by Zhang et al. [8] which adequately represents the state of knowledge and clearly specifies the purpose and motivation of taking up the topic. SAW is used in mechanical, electrical, and bioengineering [11-16]. Delay lines, converters, sensors, filters, non-contact rotary motors, and actuators are other applications of surface acoustic waves as electronic elements $[11,16]$. They reviewed the ultrasonics devices and laser-induced SAW applications, too. Droplet boundary behaviors can degrade SAW performance [12]. SAW can increase film cooling in a cylindrical hole [13]. Lamanna et al. [14] found the new application of SAW in Biosensors and Bioelectronics. They discovered conformable surface acoustic wave biosensor for E-coli fabricated on PEN plastic films. Mode conversion phenomena was used in laser-induced SAW to assess the elastic constants [15].

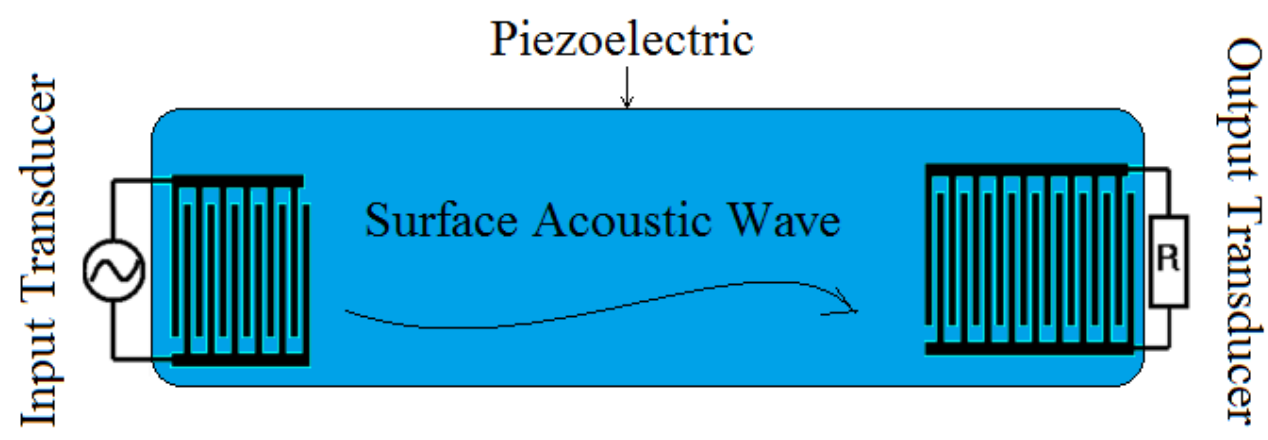

Figure 1. Top view of a typical of surface acoustic wave device, including input transducer, output transducer, and piezoelectric subtrace in a design.

The present study focuses on the change in cooling capacity of a SAW system with adding a phase change material (PCM). We aimed to investigate the effect of adding nanoparticles on fluid movement on cooling performance as it potentially provides two key advantages: increasing convective heat exchange at the electric boundary, as well as inside the fluid. Nanofluids as a mixture of fluids and nanoparticles has emerging applications in crystal growth [17] and polymers, blood and other biofluids, etc. Jamalabadi and Park study the freezing of PCM containing nanoparticles $[17,18]$. They allowed the nanofluid to undergo freezing. A consequence is that increase of thermal conductivity and decrease of the latent heat increase the convection heat transfer. But, they did not model electrically conductive fluid flows under the action of electromagnetic forces. Recently, Jamalabadi [19] presented the rational design calculation of surface acoustic wave gas sensor with and without microchannel cooling. But, phase change material with brownian effects [20] or optimization [21] are not considered yet. Fluid motion is usually affected by externally imposed electric and magnetic fields, for instance, liquid metals in fusion blankets, electrolytes in batteries, biological fluids under magnetic resonance imaging in medical examinations, etc.

The goal of the paper was that, through performed simulations and presentation of results of the magnetic nanoparticles simulation, to demonstrate that nanoparticles are beneficent in SAW application cooling. As well, the aim of the current paper was to propose a cooling method by nanoparticle-enhanced PCM (NEPCM). First, the geometry and physics of the problem are presented. Emphasis is given to Newtonian nanofluid rather than non-Newtonian nanofluid, which is seen in granular materials and granular suspensions. As well, laminar fluid flow is considered and electromagnetic instabilities are ignored. In the next step, the mathematical modeling of the proposed electro-rheological 
system is explained. Finally, by investigating the results of modeling, the performance of SAW embedded with NEPCM is discussed.

\section{Modeling}

\subsection{Cooling Part}

Figure 1 presents the SAW device design. That figure shows top view of a typical of surface acoustic wave device, including input transducer, output transducer, and piezoelectric substrate in a design. SAW devices usually are made of piezoelectric materials, and their positive and negative piezoelectric effects are used to realize signal conversion. When surface acoustic wave propagates in piezoelectric materials, there will be electromagnetic waves generated by induced charge. Therefore, when describing surface acoustic wave propagating on piezoelectric materials, it is usually necessary to consider the motion equation and Maxwell equation and couple them through piezoelectric equation. Geometry of the each circuit line is considered as a SAW cell. Figure 2 presents the SAW device cooled by NEPCM. The SAW block is next to NEPCM system. Cartesian coordinate system origin is set to left bottom corner of PCM box. As the title says, cooling and thermal management is the aim here. Based on the boundary conditions, the left wall has a heat flux and the top and bottom walls have natural convection with environment, whereas the left and right walls are adiabatic. Since the cooling of device normally is done by top surface and bottom wall, the convection with other walls is zero because of periodic boundary condition. While the phase change material will absorb heat, the heat is dissipated from the PCM. This leads to an overall cooling of the system as heat is evacuated from the top and bottom walls. Therefore, this cooling system is consistent with the general application. This will help in transient heat source system as a thermal mass, as well as a steady state.

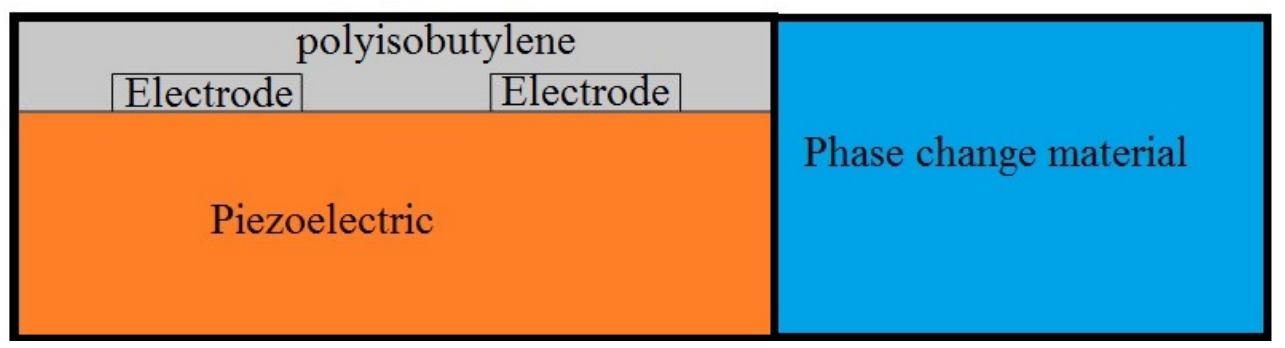

Figure 2. Geometry of the unit cell of the proposed surface acoustic wave (SAW) unit cell where cooling system is interacted with electrical part.

The PCM box has the size of $L \times H$. Figures 1 and 2 uses the color for different things. The figures are not related, and they represent same thing. Figure 1 is schematic of general device, including many cells, and Figure 2 is the real geometry modeled here, including piezoelectric cell and added fluid cell through the material. As we consider Figure 1 as ideal schematics, then, in the Figure 2, one can see the interaction of the heat and electrical fields are working in one cell. As the name of the components is presented, the mechanisms of the system or the effects of phase change material will be explained in the next section.

Nanoparticles (Graphite, $\mathrm{Ag}-\mathrm{TiO}_{2}, \mathrm{TiO}_{2}, \mathrm{CuO}, \mathrm{ZnO}, \mathrm{Fe}_{3} \mathrm{O}_{4}, \mathrm{CNF}, \mathrm{GNP}, \mathrm{GrP}, \mathrm{Gr}$ Powder, Indium Powder, $\mathrm{SiO}_{2}, \alpha$-nano-alumina, SWCNTs, MWCNTs, carbon nanofibers, and activated carbon nanosheets) are mixed by a base PCM (Paraffin wax, Capric acid, oleic acid, Tricosane, RT45, RT55, Petroleum wax, Ethanol, Liquid paraffin, poly-a-olefin, Poly carboxylic acid, organic solvents, RT42, $\mathrm{Mn}\left(\mathrm{NO}_{3}\right)_{2}$, Lauric acid, stearic acid, Ethyl transcinnamate) throughout sonication. NePCMs are prepared by two-step sonication technique. Time for sonication is from $30 \mathrm{~min}$ up to $24 \mathrm{~h}$. Surfactant (Ethanol, PolyVinylPyrrolidone-40, 1-tetradecanol, and Sodium dodecyl sulphate) is also used for better reaction.

The conservation of mass in incompressible liquid is

$$
\frac{\partial u}{\partial x}+\frac{\partial v}{\partial y}=0
$$


The conservation of horizontal momentum is

$$
\begin{array}{r}
\frac{\partial u}{\partial t}+u \frac{\partial u}{\partial x}+v \frac{\partial u}{\partial y}= \\
\frac{1}{\rho_{\mathrm{nf}}}\left(-\frac{\partial p}{\partial x}+\mu_{\mathrm{nf}} \nabla^{2} u+(\rho \beta)_{\mathrm{nf}} f_{x}\left(T-T_{\mathrm{ref}}\right)\right)-\frac{\rho_{\mathrm{s}}}{\rho_{\mathrm{nf}}} \frac{\partial \phi}{\partial x}
\end{array}
$$

with the boundary condition of horizontal velocity for left and right wall

$$
u(x=0, L)=0
$$

top and bottom wall

$$
u(y=0, H)=0 .
$$

The properties formulas are presented in Table 1. As well, the material thermo-physical properties are presented in Table 2 . The conservation of vertical momentum is

$$
\begin{array}{r}
\frac{\partial v}{\partial t}+u \frac{\partial v}{\partial x}+v \frac{\partial v}{\partial y}= \\
\frac{1}{\rho_{\mathrm{nf}}}\left(-\frac{\partial p}{\partial y}+\mu_{\mathrm{nf}} \nabla^{2} v+(\rho \beta)_{\mathrm{nf}} f_{y}\left(T-T_{\mathrm{ref}}\right)\right)-\frac{\rho_{\mathrm{s}}}{\rho_{\mathrm{nf}}} \frac{\partial \phi}{\partial y}
\end{array}
$$

with the boundary condition of vertical velocity for left and right wall

$$
v(x=0, L)=0
$$

vertical velocity for top and bottom wall

$$
v(y=0, H)=0
$$

The conservation of energy in fluid is

$$
\begin{array}{r}
\frac{\partial T}{\partial t}+u \frac{\partial T}{\partial x}+v \frac{\partial T}{\partial y}= \\
\frac{\partial}{\partial x}\left[\frac{\left(k_{\mathrm{nf} 0}+k_{\mathrm{d}}\right)}{\left(\rho c_{\mathrm{p}}\right)_{\mathrm{nf}}} \frac{\partial T}{\partial x}\right]+\frac{\partial}{\partial y}\left[\frac{\left(k_{\mathrm{nf} 0}+k_{\mathrm{d}}\right)}{\left(\rho c_{\mathrm{p}}\right)_{\mathrm{nf}}} \frac{\partial T}{\partial y}\right],
\end{array}
$$

where boundary condition of the thermal field is for the left wall

$$
q(x=0)=\frac{\partial T(x=0)}{\partial x}
$$

for the adiabatic right wall

$$
\frac{\partial T(x=L)}{\partial x}=0
$$

for the adiabatic top wall

$$
-k \frac{\partial T(y=H)}{\partial y}=h\left(T(y=H)-T_{\infty}\right)
$$

for the adiabatic bottom wall

$$
k \frac{\partial T(y=0)}{\partial y}=h\left(T(y=0)-T_{\infty}\right) .
$$

To simulate the phase change process, the temperature is the primary dependent variable in the fluid energy Equation (8). To consider sensible heat and latent heat, effective heat capacity of NEPCM is defined temperature dependent parameter in three zones of 
the fluid, solid, and pseudo mushy zone. In the solid region, the energy equation reads Equation (15), and, in the fluid region, the energy equation reads Equation (8). In the mushy region (between solid and fluid), the solid energy equation should be modified by $\frac{L}{c_{\mathrm{M}}} \frac{\partial f_{\mathrm{S}}}{\partial t}$ source term, where $f_{\mathrm{S}}=\frac{X_{\mathrm{L}}-x}{X_{\mathrm{L}}-X_{\mathrm{S}}}$. The heat source term $\left(\frac{L}{c_{\mathrm{M}}} \frac{\partial f_{\mathrm{S}}}{\partial t}\right)$ accounts for the transient release of latent heat within the mushy region that is represented by the time rate change of solid fraction, which is usually considered as a known function of location.

The implicit discretization of the general form of the energy equation can be used. Some references used the Enthalpy method, but, as here the uniform heat capacity is considered for each material, the effective heat capacity method is worked, as well. The Prandtl number $(\mathrm{Pr})$ and the Rayleigh number $(\mathrm{Ra})$ are important in the natural convection systems. Prandtl number is defined as

$$
\operatorname{Pr}=\frac{\mu_{f}}{\rho_{f} \alpha_{f}},
$$

and Rayleigh number is

$$
R a=\frac{g \rho_{f} \beta_{f} \Delta T H^{3}}{\alpha_{f} \mu_{f}} .
$$

Table 1. Nanofluid property formulas.

\begin{tabular}{cc}
\hline Nanofluid Property & Formula \\
\hline$\rho$ & $(1-\alpha) \rho_{\mathrm{f}}+\alpha \rho_{\mathrm{s}}$ \\
$\rho c_{\mathrm{p}}$ & $(1-\alpha)\left(\rho c_{\mathrm{p}}\right)_{\mathrm{f}}+\alpha\left(\rho c_{\mathrm{p}}\right)_{\mathrm{s}}$ \\
$\rho \beta$ & $(1-\alpha)(\rho \beta)_{\mathrm{f}}+\alpha(\rho \beta)_{\mathrm{s}}$ \\
$\mu$ & $\frac{\mu_{\mathrm{f}}}{(1-\alpha)^{2.5}}$ \\
$k$ & $k_{\mathrm{f}} \frac{k_{\mathrm{s}}+2 k_{\mathrm{f}}-2 \alpha\left(k_{\mathrm{f}}-k_{\mathrm{s}}\right)}{k_{\mathrm{s}}+2 k_{\mathrm{f}}+\alpha\left(k_{\mathrm{f}}-k_{\mathrm{s}}\right.}+C\left(\rho c_{\mathrm{p}}\right)_{\mathrm{nf}} \sqrt{u^{2}+v^{2}} \alpha d_{\mathrm{p}}$ \\
$\rho L$ & $(1-\alpha)(\rho L)_{\mathrm{f}}$ \\
\hline
\end{tabular}

Table 2. Material thermo-physical properties [18].

\begin{tabular}{ccccccc}
\hline Material & $\mathbf{k}$ & $\mathbf{C}$ & $\boldsymbol{\rho}$ & $\boldsymbol{\beta}$ & $\boldsymbol{H}_{f}$ & $\boldsymbol{\mu}$ \\
\hline & $\mathbf{W} / \mathbf{m} \cdot \mathbf{K}$ & $\mathbf{k J} / \mathbf{k g} \cdot \mathbf{K}$ & $\mathbf{~ k g} / \mathbf{m}^{\mathbf{3}}$ & $\left.\mathbf{( K}^{-\mathbf{1}}\right)$ & $\mathbf{J} / \mathbf{k g}$ & \\
\hline fluid TH29 & 0.53 & 2.2 & 1530 & $2 \times 10^{-4}$ & 187 & $5.33 \times 10^{-3}$ \\
solid TH29 & 1.09 & 1.4 & 1719 & & 187 & \\
Cu & 400 & 0.383 & 8954 & $1.67 \times 10^{-5}$ & & \\
\hline
\end{tabular}

The status of the system regarding the initial conditions and final conditions is important. The problem is presented as time dependent and will start in a temperature same as environment temperature initial conditions and end at an arbitrary point. The final condition is achieved when the system stabilizes at the end of solid NEPCM.

Table 2 mentions TH29, a commercially available PCM. Based on the description presented before, here, a standard PCM material is used as a base, and the nanoparticles are added to it. This brings to the question regarding the nanoparticles themselves because there are a lot of different nanoparticles that can be used. Here, the $\mathrm{Cu}$ nanoparticles is assumed, all dissolved in the base material with the relative concentration $\alpha$. For creation that different materials should be mixed, such as surfactant, that here is neglected which influences the results. The $\mathrm{Cu}$ chosen is a standard nano-powder, in market. This is also a standard, like the TH29. In fact, the paper presents a so-called effective PCM, i.e., an artificial substance which is assigned with certain properties just because nanoparticles are used. So, this is just one more work on, "nanofluids" without any experimental background. 


\subsection{Surface Acoustic Wave in Electrical Part}

The conservation of energy in solid is

$$
\frac{\partial T}{\partial t}=\frac{\partial}{\partial x}\left[\frac{k_{\mathrm{s}}}{\left(\rho c_{\mathrm{s}}\right)} \frac{\partial T}{\partial x}\right]+\frac{\partial}{\partial y}\left[\frac{k_{\mathrm{s}}}{\rho c_{\mathrm{s}}} \frac{\partial T}{\partial y}\right],
$$

where all walls other than tight wall are adiabatic.

Figure 2 presents the proposed geometry of the SAW unit cell, including the NEPCM part and the electrical part. The boundary condition of the electrical part is plotted with more details in Figure 3. The particle motion in a piezoelectric medium is based on elastic wave equation calculated by

$$
\rho \frac{\partial^{2} u_{i}}{\partial t^{2}}=\frac{\partial T_{i j}}{\partial x_{j}},
$$

where the stress field is

$$
T_{i j}=s_{i j k l}^{E} S_{k l}+d_{i k l} E_{k} .
$$

The above equation shows how the elastic constant, piezoelectric constants, and stress field are contributing to the electric field of the proposed model.

$$
\Phi=0
$$

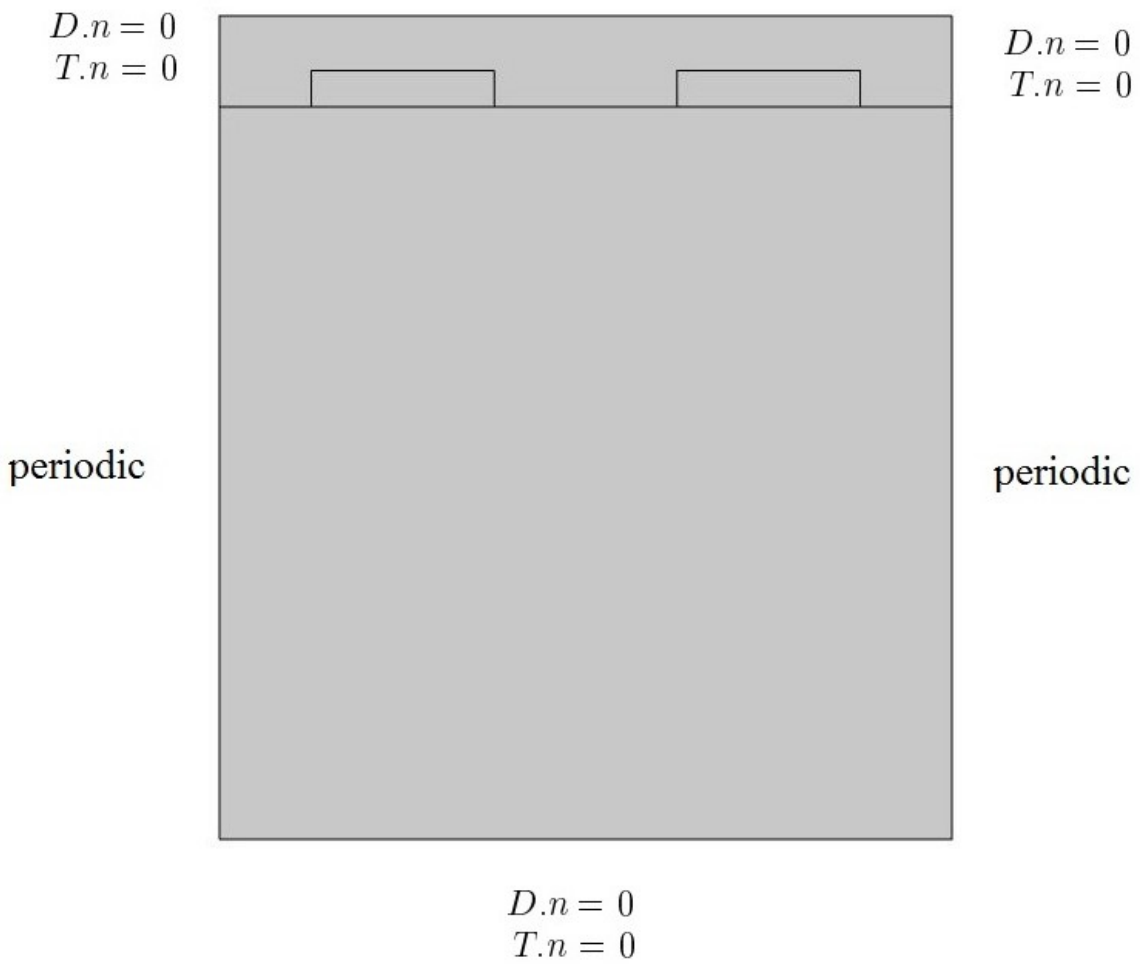

Figure 3. Geometry of the electric part of the proposed SAW unit cell and electrical boundary condition.

In matrix form:

$$
T_{i j}=\left[\begin{array}{l}
T_{11} \\
T_{12} \\
T_{13} \\
T_{22} \\
T_{23} \\
T_{33}
\end{array}\right] .
$$

Strain field:

$$
S_{i j}=\left(u_{i, j}+u_{j, i}\right) / 2 .
$$


In matrix form:

$$
S_{i j}=\left[\begin{array}{l}
S_{11} \\
S_{12} \\
S_{13} \\
S_{22} \\
S_{23} \\
S_{33}
\end{array}\right] .
$$

As the electromagnetic wave velocity is several orders higher than that of surface acoustic wave, the electromagnetic field coupled with surface acoustic wave can be approximately regarded as an electrostatic field, since the electric field is

$$
E_{i}=-\phi, i
$$

In matrix form:

$$
E_{i}=-\left[\begin{array}{l}
\phi, 1 \\
\phi, 2 \\
\phi, 3
\end{array}\right]
$$

elastic constants are

$$
s_{i j k l}^{E}=\left[\begin{array}{cccccc}
s_{11}^{E} & s_{12}^{E} & s_{13}^{E} & 0 & 0 & 0 \\
s_{12}^{E} & s_{11}^{E} & s_{13}^{E} & 0 & 0 & 0 \\
s_{13}^{E} & s_{13}^{E} & s_{33}^{E} & 0 & 0 & 0 \\
0 & 0 & 0 & s_{44}^{E} & 0 & 0 \\
0 & 0 & 0 & 0 & s_{44}^{E} & 0 \\
0 & 0 & 0 & 0 & 0 & s_{66}^{E}
\end{array}\right]
$$

piezoelectric constants are

$$
d_{i j k}=\left[\begin{array}{cccccc}
0 & 0 & 0 & 0 & d_{15} & 0 \\
0 & 0 & 0 & d_{15} & 0 & 0 \\
d_{31} & d_{31} & d_{33} & 0 & 0 & 0
\end{array}\right] ;
$$

or stress field is

$$
\begin{gathered}
T_{i j}=\left[\begin{array}{cccccc}
s_{11}^{E} & s_{12}^{E} & s_{13}^{E} & 0 & 0 & 0 \\
s_{12}^{E} & s_{11}^{E} & s_{13}^{E} & 0 & 0 & 0 \\
s_{13}^{E} & s_{13}^{E} & s_{33}^{E} & 0 & 0 & 0 \\
0 & 0 & 0 & s_{44}^{E} & 0 & 0 \\
0 & 0 & 0 & 0 & s_{44}^{E} & 0 \\
0 & 0 & 0 & 0 & 0 & s_{66}^{E}
\end{array}\right] S_{k l}+ \\
\\
{\left[\begin{array}{ccccccc}
0 & 0 & 0 & 0 & d_{15} & 0 \\
0 & 0 & 0 & d_{15} & 0 & 0 \\
d_{31} & d_{31} & d_{33} & 0 & 0 & 0
\end{array}\right] E_{k}}
\end{gathered}
$$

with

$$
\rho \frac{\partial^{2} u_{i}}{\partial t^{2}}=s_{i j k l}^{E} \frac{\partial^{2} u_{k}}{\partial x_{j} \partial x_{l}}+d_{i j k} \frac{\partial^{2} \phi}{\partial x_{j} \partial x_{k}} .
$$

Electric field in a piezoelectric medium is calculated by the divergence of the electrical displacement vector D (must be equal to zero), where electric displacement is

$$
D_{i}=d_{i k l} S_{k l}+\varepsilon_{i k}^{T} E_{k}
$$


dielectric permittivity constants

$$
\varepsilon_{i k}^{T}=\left[\begin{array}{ccc}
\varepsilon_{11}^{T} & 0 & 0 \\
0 & \varepsilon_{22}^{T} & 0 \\
0 & 0 & \varepsilon_{33}^{T}
\end{array}\right]
$$

electric displacement

$$
D_{i}=\left[\begin{array}{cccccc}
0 & 0 & 0 & 0 & d_{15} & 0 \\
0 & 0 & 0 & d_{15} & 0 & 0 \\
d_{31} & d_{31} & d_{33} & 0 & 0 & 0
\end{array}\right] T_{k l}+\left[\begin{array}{ccc}
\varepsilon_{11}^{T} & 0 & 0 \\
0 & \varepsilon_{22}^{T} & 0 \\
0 & 0 & \varepsilon_{33}^{T}
\end{array}\right] E_{k} .
$$

Electric field in a piezoelectric medium is calculated by

$$
d_{j k l} \frac{\partial^{2} u_{k}}{\partial x_{j} \partial x_{l}}=\varepsilon_{j k} \frac{\partial^{2} \phi}{\partial x_{j} \partial x_{k}} .
$$

The boundary conditions for electric potential are straightforward (see Figure 3). So, the electric potential is equal to a specific value for the emitting electrode, and it is equal to zero for the bottom wall as a collector electrode. It is not so easy to obtain the boundary conditions for the electric space charge density.

\section{Results}

The first important point in any computational technique is the meshing. Width and height of SAW cell and NEPCM cell are $4(\mu \mathrm{m})$, as presented in Table 3. Uniform meshing in both parts i.e., SAW cell and NEPCM cell are used to assure the validity of a simulation and the independence of the solution to the meshing. The modeled geometry is also presented in Figure 2. It is clear that the SAW and NEPCM were modeled and solved together.

Table 3. Polyisobutylene data.

\begin{tabular}{ccc}
\hline Parameter & Expression & Explanation \\
\hline $\mathrm{T}$ & $25\left[{ }^{\circ} \mathrm{C}\right]$ & Environment temperature \\
$\rho_{P I B}$ & $0.918\left[\mathrm{~g} / \mathrm{cm}^{3}\right]$ & Density of polyisobutylene \\
$E_{P I B}$ & $10[\mathrm{GPa}]$ & Young's modulus of polyisobutylene \\
$v_{P I B}$ & 0.48 & Poisson's ratio of polyisobutylene \\
$\epsilon_{P I B}$ & 2.2 & Relative permittivity of polyisobutylene \\
$v_{\text {Rayleigh }}$ & $3488[\mathrm{~m} / \mathrm{s}]$ & Rayleigh wave velocity \\
$W$ & $4[\mu \mathrm{m}]$ & Width of unit cell \\
$f_{0}$ & $\frac{v_{\text {Rayleigh }}}{\mathrm{W}}$ & Estimated SAW frequency \\
$t_{P I B}$ & $0.5[\mu \mathrm{m}]$ & polyisobutylene thickness \\
\hline
\end{tabular}

There is too much difficulty in the part of preparing nanoliquids. The information on the used nanoparticles and base fluids (CAS number, manufacturer, etc.) is important in any experiment. Here, limited concentration/mixing ratio is used to avoid nonlinear effects. Given the limit of Newtonian fluids, nanoliquids concentration were selected. In experiment, it need some time for the produced samples to be stable. As well, there are many ways determined to prove the stability over time, and the sonication parameters (amplitude, energy) are important on such stability. The most important parameters of the used base liquids and nanoparticles are given in Tables 2 and 3.

A lot of effort is placed on enumerating the equations in previous part, but, finally, it is clear that they are mass (Equation (1)), momentum (Equations (2) and (5)), energy governing equations (Equations (8) and (15)), elastic wave equation (Equation (26)), and piezoelectric relation (Equation (30)) solved by using the finite element method. 
Figures 4 and 5 are mode shapes, and they are normalized to a maximum. Figure 4 is entirely having aurora borealis representation, and Figure 5 simply uses rain bow light legend representation. The first six modes of SAW problem are plotted in Figure 4 from a (mode 1) to $\mathrm{f}$ (mode 6). The first 6 modes of SAW is presented in Table 4.

Table 4. First 6 modes of SAW system.

\begin{tabular}{|c|c|c|}
\hline Property & Units & Value \\
\hline Eigenfrequency & $\mathrm{Hz}$ & $2.4664 \times 10^{8}$ \\
\hline Participation factor, normalized, $\mathrm{X}$-translation & - & $-2.4946 \times 10^{-4}$ \\
\hline Participation factor, normalized, Y-translation & - & $7.0013 \times 10^{-6}$ \\
\hline Participation factor, normalized, Z-rotation & - & $1.4234 \times 10^{-10}$ \\
\hline Effective modal mass, $X$-translation Effective modal mass & $\mathrm{kg}$ & $6.2228 \times 10^{-8}$ \\
\hline Y-translation $(\mathrm{kg})$ Effective modal mass & $\mathrm{kg}$ & $4.9018 \times 10^{-11}$ \\
\hline Effective modal mass, Z-rotation & $\mathrm{kg} \cdot \mathrm{m}^{2}$ & $2.0260 \times 10^{-20}$ \\
\hline Eigenfrequency & $\mathrm{Hz}$ & $4.0749 \times 10^{8}$ \\
\hline Participation factor, normalized, $\mathrm{X}$-translation & - & $-6.9887 \times 10^{-6}$ \\
\hline Participation factor, normalized, Y-translation & - & $-2.4954 \times 10^{-4}$ \\
\hline Participation factor, normalized, Z-rotation & - & $4.0343 \times 10^{-12}$ \\
\hline Effective modal mass, $\mathrm{X}$-translation Effective modal mass & $\mathrm{kg}$ & $4.8841 \times 10^{-11}$ \\
\hline Y-translation $(\mathrm{kg})$ Effective modal mass & $\mathrm{kg}$ & $6.2272 \times 10^{-8}$ \\
\hline Effective modal mass, Z-rotation & $\mathrm{kg} \cdot \mathrm{m}^{2}$ & $1.6275 \times 10^{-23}$ \\
\hline Eigenfrequency & $\mathrm{Hz}$ & $7.3261 \times 10^{8}$ \\
\hline Participation factor, normalized, $\mathrm{X}$-translation & - & $-8.2315 \times 10^{-5}$ \\
\hline Participation factor, normalized, Y-translation & - & $-2.1961 \times 10^{-6}$ \\
\hline Participation factor, normalized, Z-rotation & - & $2.4716 \times 10^{-10}$ \\
\hline Effective modal mass, $\mathrm{X}$-translation Effective modal mass & $\mathrm{kg}$ & $6.7758 \times 10^{-9}$ \\
\hline Y-translation $(\mathrm{kg})$ Effective modal mass & $\mathrm{kg}$ & $4.8227 \times 10^{-12}$ \\
\hline Effective modal mass, Z-rotation & $\mathrm{kg} \cdot \mathrm{m}^{2}$ & $6.1090 \times 10^{-20}$ \\
\hline Eigenfrequency & $\mathrm{Hz}$ & $8.7055 \times 10^{8}$ \\
\hline Participation factor, normalized, X-translation & - & $1.0546 \times 10^{-11}$ \\
\hline Participation factor, normalized, Y-translation & - & $-7.1771 \times 10^{-13}$ \\
\hline Participation factor, normalized, Z-rotation & - & $-1.9653 \times 10^{-10}$ \\
\hline Effective modal mass, $\mathrm{X}$-translation Effective modal mass & $\mathrm{kg}$ & $1.1122 \times 10^{-22}$ \\
\hline Y-translation $(\mathrm{kg})$ Effective modal mass & $\mathrm{kg}$ & $5.1511 \times 10^{-25}$ \\
\hline Effective modal mass, Z-rotation & $\mathrm{kg} \cdot \mathrm{m}^{2}$ & $3.8625 \times 10^{-20}$ \\
\hline Eigenfrequency & $\mathrm{Hz}$ & $8.7667 \times 10^{8}$ \\
\hline Participation factor, normalized, $\mathrm{X}$-translation & - & $-3.5058 \times 10^{-12}$ \\
\hline Participation factor, normalized, Y-translation & - & $-4.8362 \times 10^{-13}$ \\
\hline Participation factor, normalized, Z-rotation & - & $4.8769 \times 10^{-11}$ \\
\hline Effective modal mass, $\mathrm{X}$-translation Effective modal mass & $\mathrm{kg}$ & $1.2291 \times 10^{-23}$ \\
\hline Y-translation (kg) Effective modal mass & $\mathrm{kg}$ & $2.3389 \times 10^{-25}$ \\
\hline Effective modal mass, Z-rotation & $\mathrm{kg} \cdot \mathrm{m}^{2}$ & $2.3784 \times 10^{-21}$ \\
\hline Eigenfrequency & $\mathrm{Hz}$ & $1.1328 \times 10^{9}$ \\
\hline Participation factor, normalized, $\mathrm{X}$-translation & - & $-3.9139 \times 10^{-5}$ \\
\hline Participation factor, normalized, Y-translation & - & $3.1356 \times 10^{-6}$ \\
\hline Participation factor, normalized, Z-rotation & - & $-5.0336 \times 10^{-11}$ \\
\hline Effective modal mass, $\mathrm{X}$-translation Effective modal mass & $\mathrm{kg}$ & $1.5319 \times 10^{-9}$ \\
\hline Y-translation $(\mathrm{kg})$ Effective modal mass & $\mathrm{kg}$ & $9.8321 \times 10^{-12}$ \\
\hline Effective modal mass, Z-rotation & $\mathrm{kg} \cdot \mathrm{m}^{2}$ & $2.5337 \times 10^{-21}$ \\
\hline
\end{tabular}


(a)

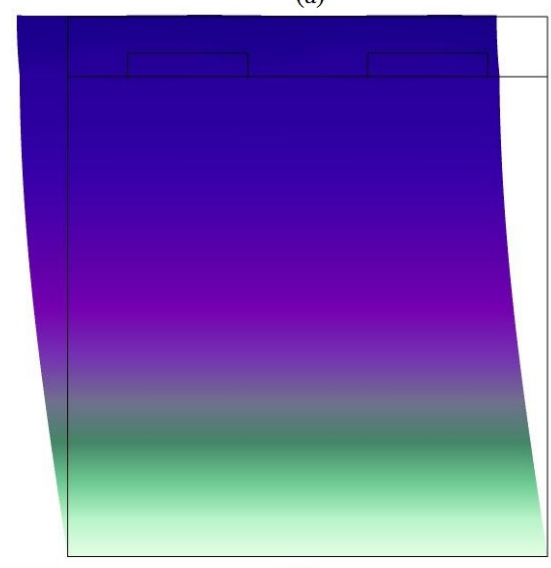

(c)

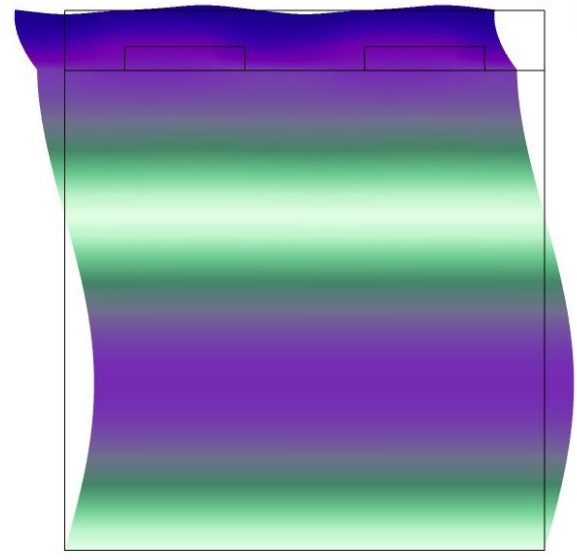

(e)

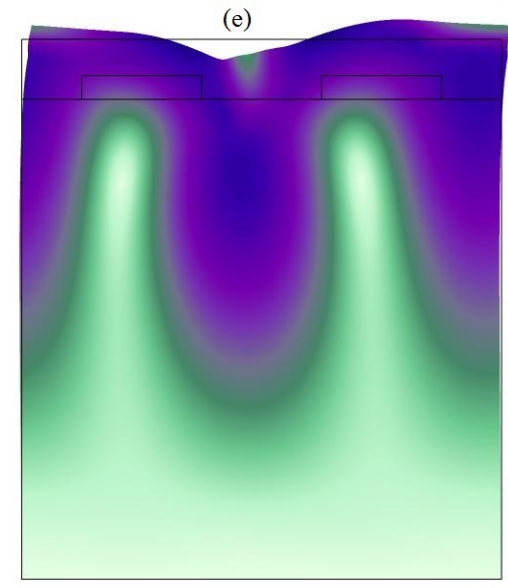

(b)

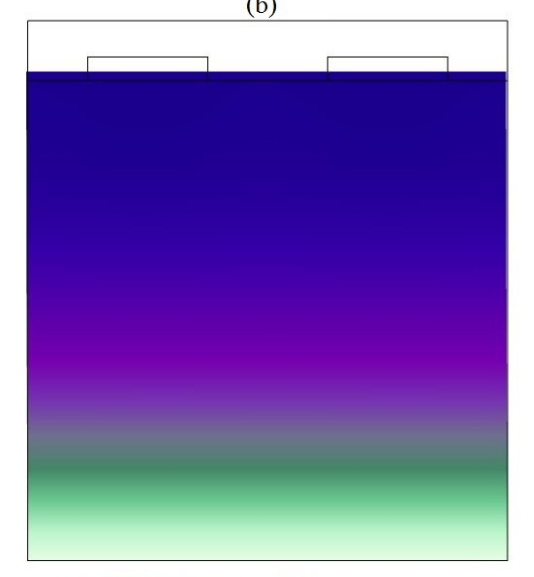

(d)

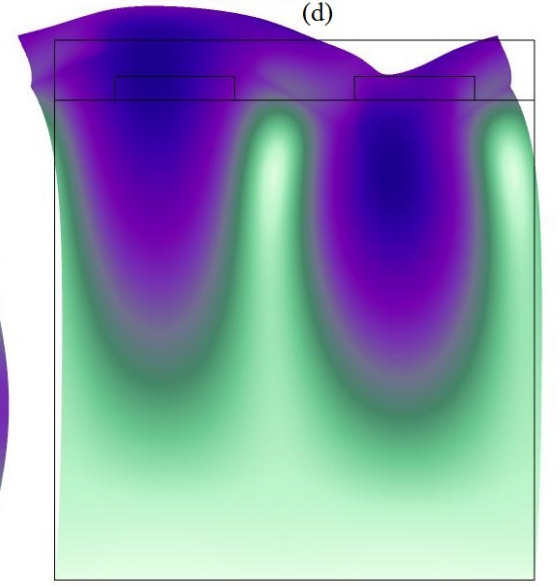

(f)

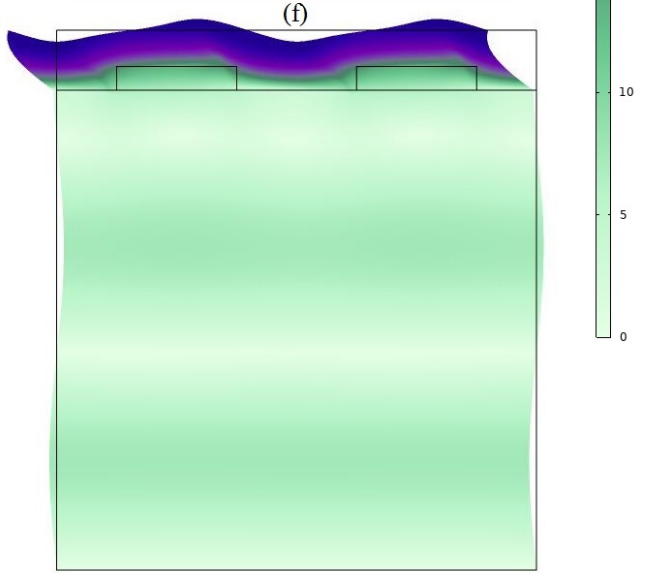

Figure 4. First six modes of SAW problem with cooling: (a) mode 1, (b) mode 2, (c) mode 3, (d) mode 4, (e) mode 5, (f) mode 6 .

Detailed explanation of various modes in rational design calculation of surface acoustic wave gas sensor are discussed in Reference [19]. The first six modes of SAW device are at $246.64,407.49,732.61,870.55,876.67$, and $1132.8 \mathrm{MHz}$. Electric potential modes are plotted in Figure 5. 
(a)

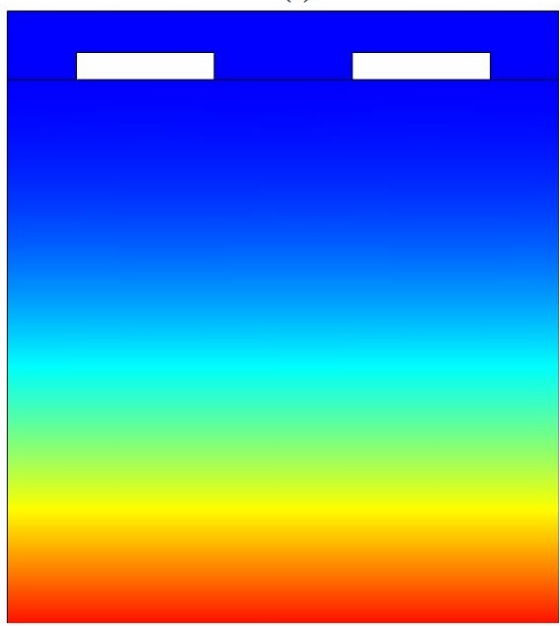

(c)

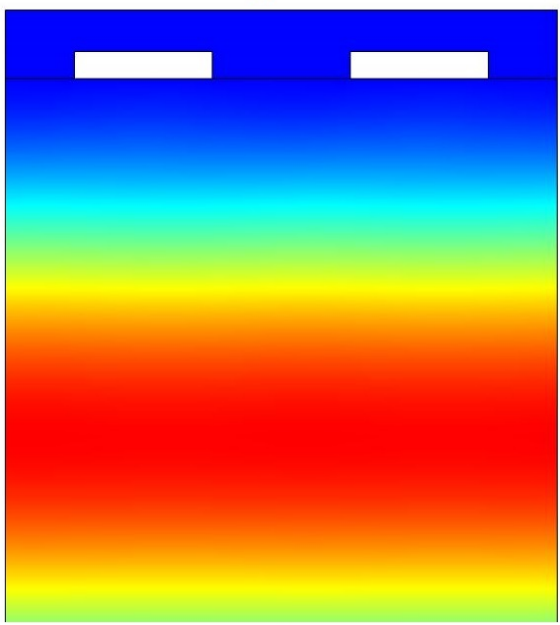

(e)

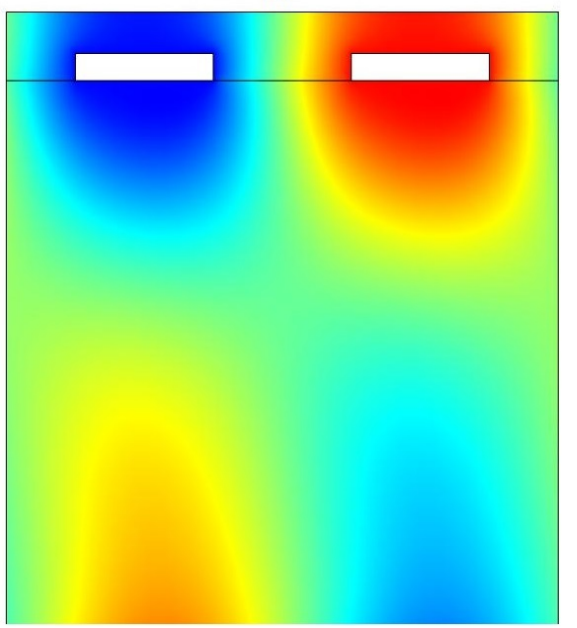

(b)

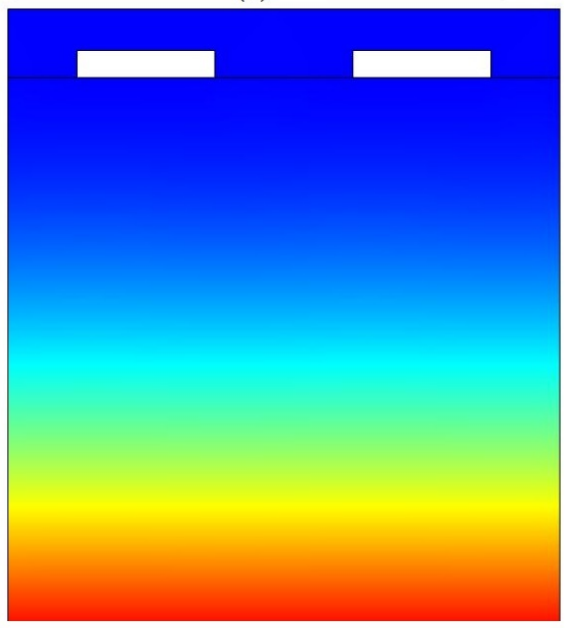

(d)

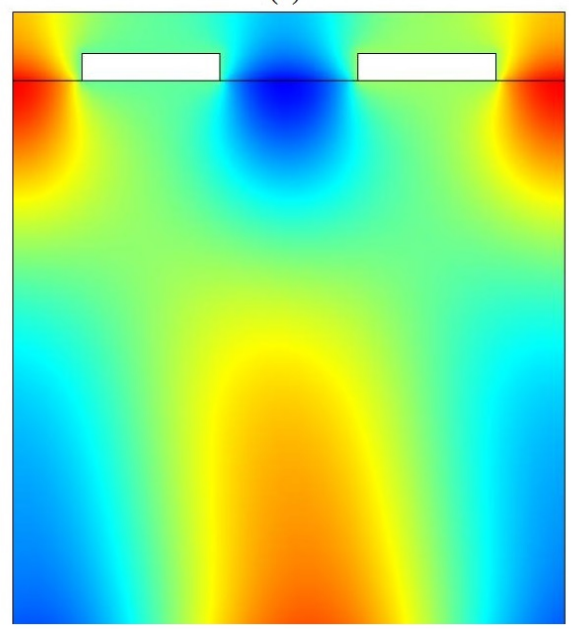

(f)

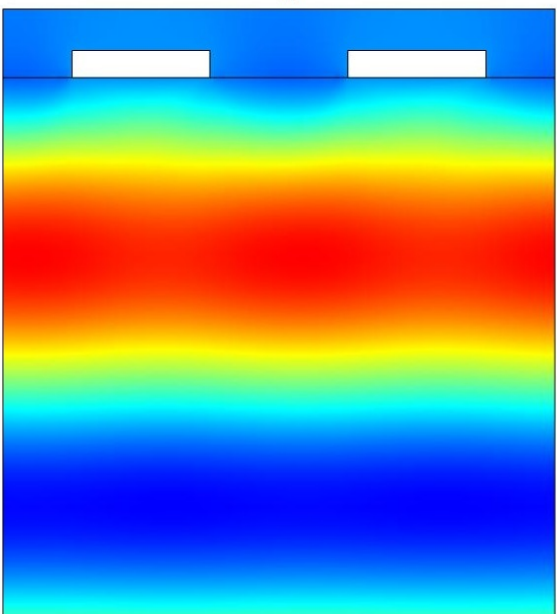

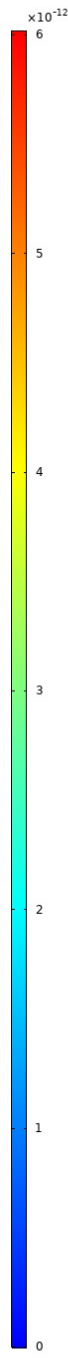

Figure 5. Electric potential: (a) mode 1, (b) mode 2, (c) mode 3, (d) mode 4, (e) mode 5, (f) mode 6.

The finite element method is used to solve problem. The relaxation factors for the velocity components, pressure correction, thermal energy, and liquid fraction were 0.5, $0.3,1$, and 0.9 , respectively. To benchmark the problem, previous work of Jamalabadi and Park [18] is used. Jamalabadi and Park [18] applied the well-known software FLUENT to simulate the problem of melting in square cavity. The cavity of fluid at the right of the electric part is filled with nanofluid that is a mixture of an inorganic hydrated salt TH29 PCM [18] and solid copper nanoparticles. The TH29 is made by an inorganic PCM 
composed primarily of calcium chloride hexahydrate $(\mathrm{CaCl} 26 \mathrm{H} 2 \mathrm{O})$. With different left and top wall temperatures, an unsteady buoyancy-driven convective flow accompanying with phase change is formed in the cavity. Three particle volume fractions are considered. The associated thermophysical properties of PCM, nanoparticle and nanofluid are given in Tables 1 and 2 (for more details, see [18]). As seen in Figure 6, both methods are in a good agreement, and little difference is caused by considering the Brownian effect in Jamalabadi and Park [18]. The used finite element method is compared to another paper (from the same author) that uses FLUENT, and it shows the validity of method in fluid part, as well.

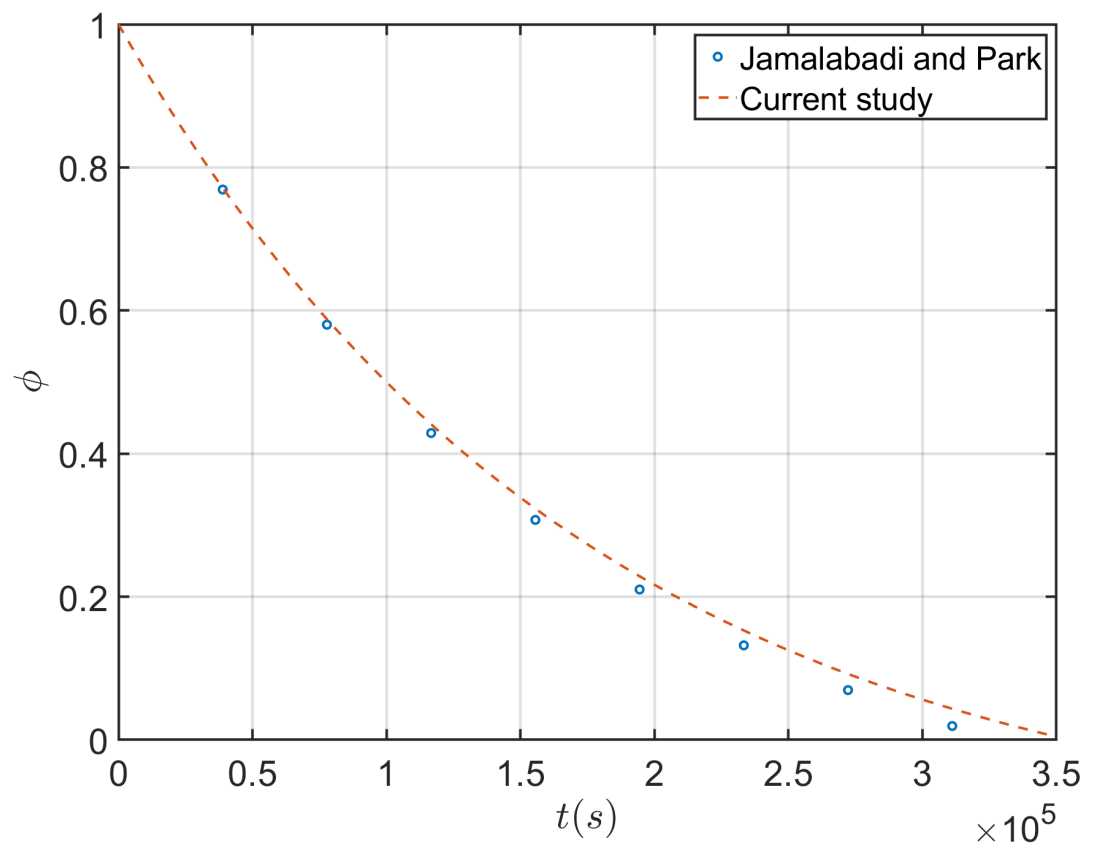

Figure 6. Comparison of the results of current method with Jamaabadi and Park [18].

Temperature distribution in SAW with cooling is plotted in Figure 7. As shown, the temperature is raised rapidly near the electrodes as the absorbed electromagnetic radiation in the circuit is converted to ohmic loss in conductors.

As time goes on, the temperature affected zone develops throughout the medium. Temperature distribution in SAW with cooling at higher power is plotted in Figure 8.

The initial conditions and final conditions are shown in Figures 9 and 10. The problem is presented as time dependent but starts in Figure 9 at arbitrary initial condition, which is 50 percent solid-50 percent liquid, and the system is at equilibrium temperature with environment and ends at an arbitrary point, as shown in Figure 10. This final condition is achieved after some time, and the system will continue to melt all NEPCM, and temperature keeps rising.

Initial condition of PCM cell contours of dimensionless temperature, contours of dimensionless pressure, velocity vector, contours of velocity magnitude is plotted in Figure 9. Figure shows the profiles though time. As time goes on, the melted zone is extended through the volume and the shape of liquid PCM is converted from rectangular to a deformed polygon as the natural convection zone is shaped in the liquid material.

Time dependency of the maximum temperature in the system shows that by considering PCM the temperature increase has some stop at the melting point of the PCM. After all PCM material is melted, again the maximum temperature in the system will increase. That capability can help the system to endure the high electrical load or some transient problem in electric side. But it will not serve as an infinite heat sink and has some limitations. By increase of nanoparticle dope on the system, the heat transfer at the interface of solid and liquid (left wall of PCM cavity) increases, and higher amount of heat is removed from the SAW device, but, at the same time, PCM heat latency is consumed 
sooner. NEPCM cannot serve as a high thermal inertia for the thermal management of the device and has some limitations. Change of volume fraction of the system with the time can show the time delay that NEPCM material can provide. Final condition of PCM cell, contours of dimensionless temperature, contours of dimensionless pressure, velocity vector, and contours of velocity magnitude are plotted in Figure 10.

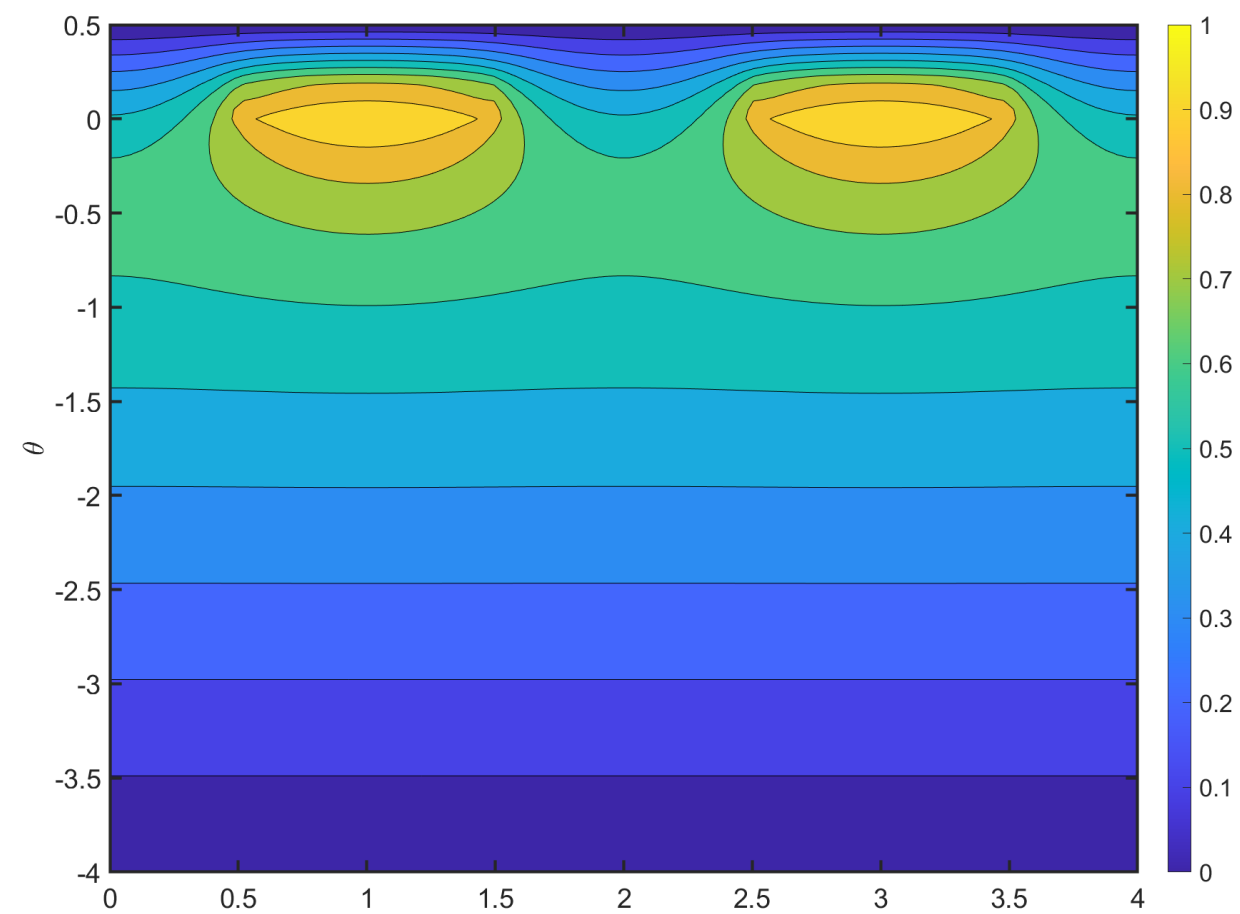

Figure 7. Temperature distribution in SAW with cooling at the initial steps of applying resonance power.

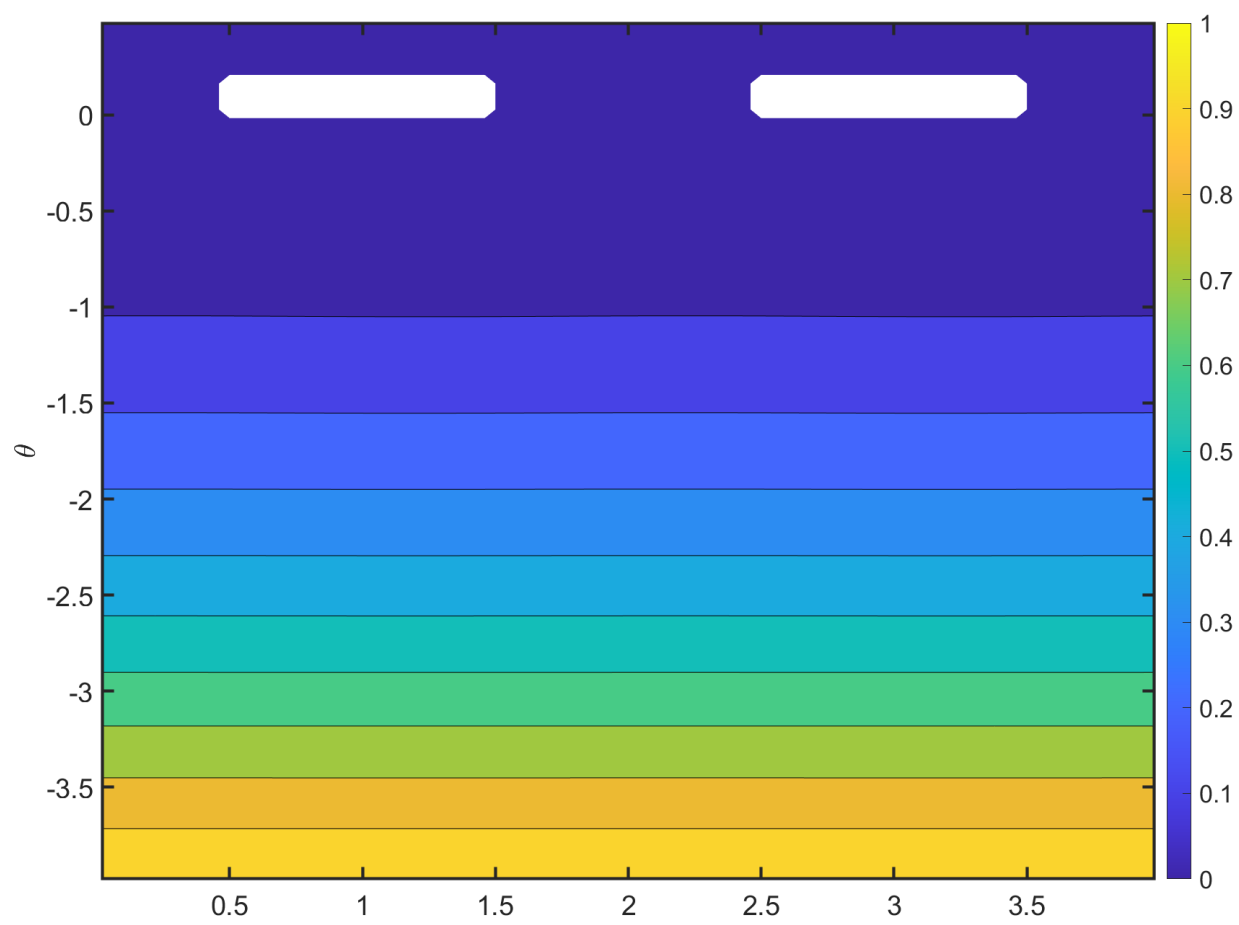

Figure 8. Temperature distribution in SAW with cooling at higher power while cooling from top. 
Figures $9 \mathrm{~d}$ and $10 \mathrm{~d}$ do not match the velocity vectors of Figures $9 \mathrm{c}$ and $10 \mathrm{c}$, as they are vectors and scalars. Only the total magnitude of velocity is presented in (d), rather than the vertical component of velocity magnitude. This is easily seen in the bottom and top part of $(\mathrm{d})$, where no velocity exists.

(a)

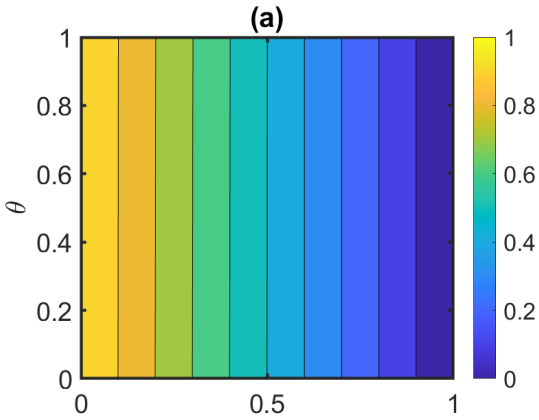

(c)

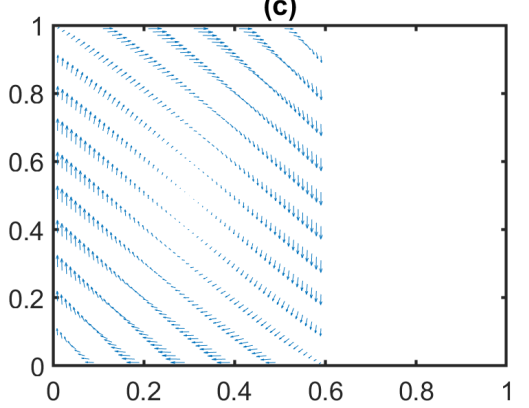

(b)

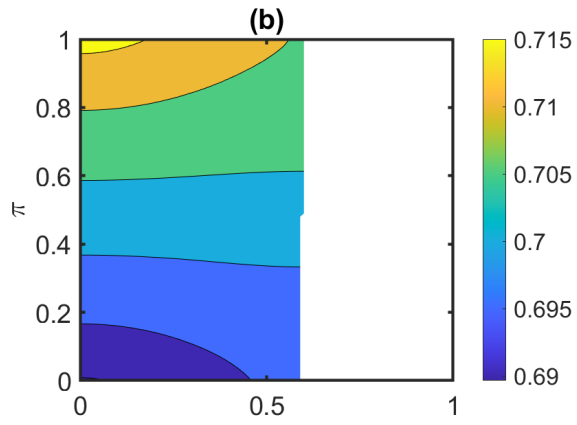

(d)

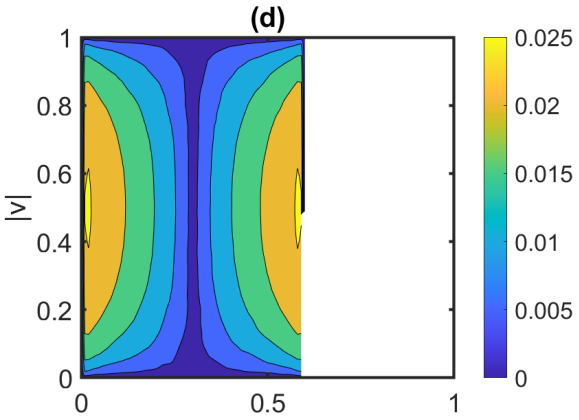

Figure 9. Initial condition of phase change material (PCM) cell: (a) contours of dimensionless temperature, (b) contours of dimensionless pressure, (c) velocity vector, (d) contours of velocity magnitude.

(a)

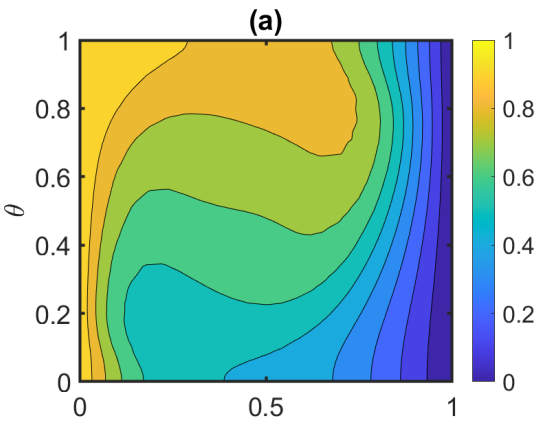

(c)

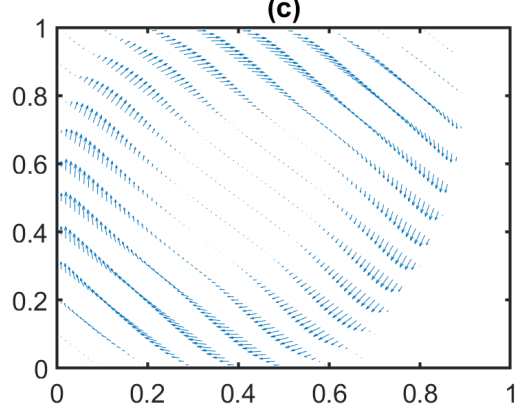

(b)

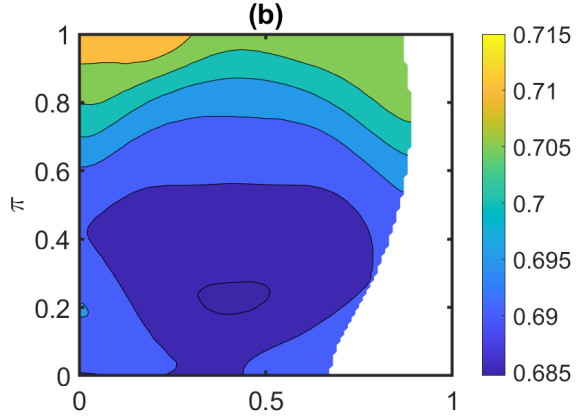

(d)

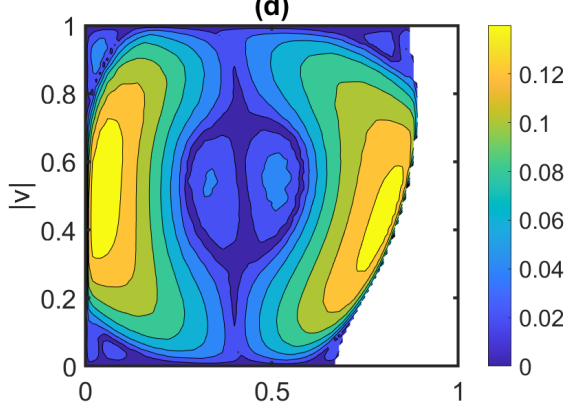

Figure 10. Final condition of PCM cell: (a) contours of dimensionless temperature, (b) contours of dimensionless pressure, $(\mathbf{c})$ velocity vector, $(\mathbf{d})$ contours of velocity magnitude. 
As stated in the introduction section, the speciality and difference in current approach is using NEPCM for SAW cooling. To make all of beneficial aspects as clear as possible to the readers, the review of Zhang et al. [8] is recommended, which performs a critical survey of what has been done up to this point in the scientific literature, and it would be clear there is a precise gap in the current state of knowledge that needs to be filled, a gap that is being addressed by current research. They show that a maximum temperature difference between the hot and cold sections of $23^{\circ} \mathrm{C}$ is obtained when the input electric power of the opposing acoustic driver was $17 \%$ of the power of the initial SAW, where the impedances and impedance angles on both ends of the regenerator are matched but the acoustic field traveling wave characteristics are still sufficient for traveling wave device operation.

Time dependency of maximum temperature is plotted in Figure 11. The boundary conditions are all constant as a function of time (steady state) such that a steady state final condition should be achievable if the system was cooled. Here, a final condition is not reachable as the system will simply continuously heat up. It would seem that the advantage of using a PCM is its ability to efficiently manage temporary spikes in temperature caused by a transient input. As stated in the abstract, the results show that the NEPCM causes heat transfer improvement up to $10 \%$. This is a comparison with a PCM in the absence of nanoparticles, and PCM with $2 \%$ of nanoparticles.

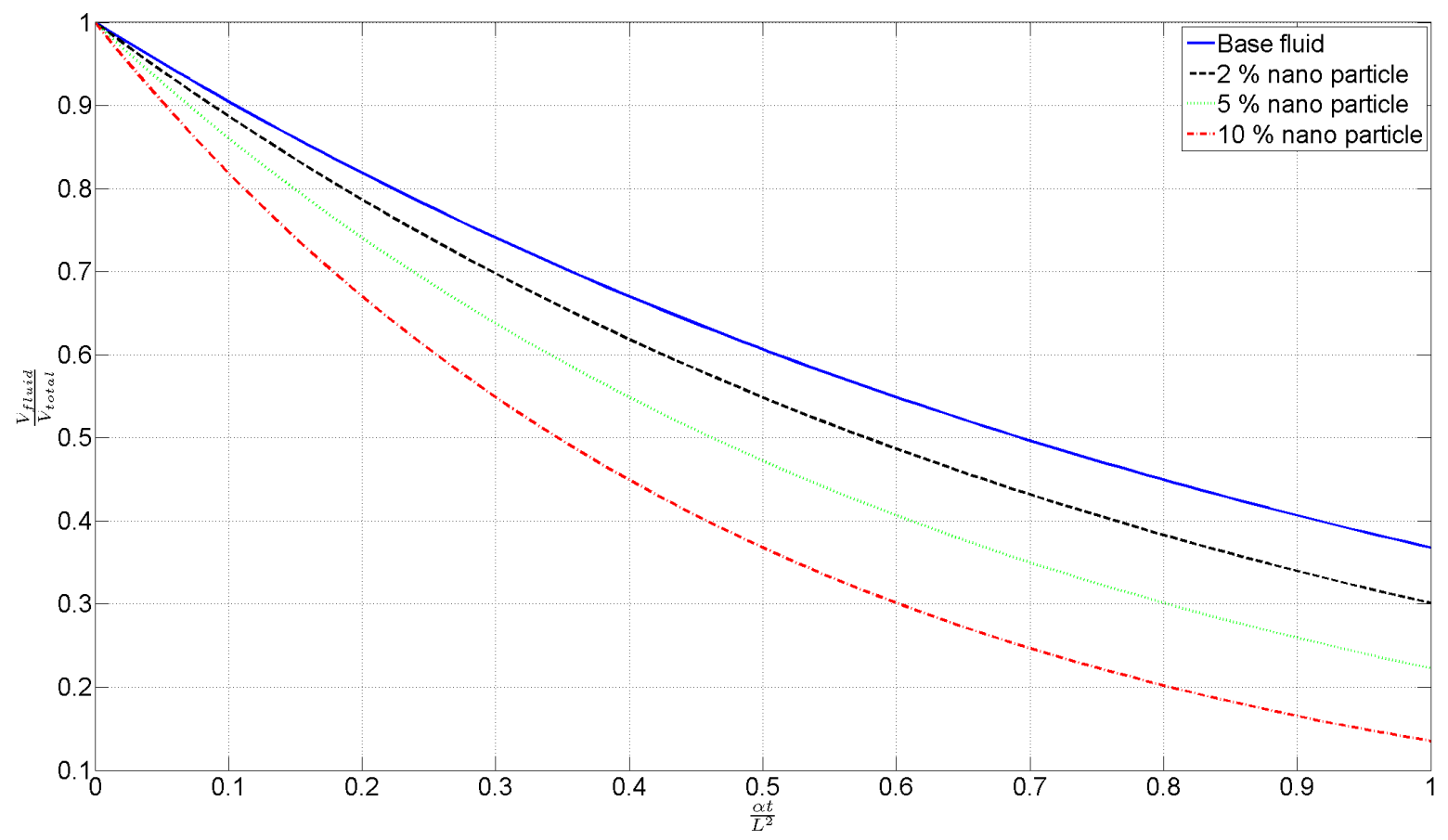

Figure 11. Time dependency of fluid volume fraction.

As well time dependency of maximum temperature is plotted in Figure 12. Figures 11 and 12 are in the same time but different y-axes, and they clearly are different graphs. This makes it clear what the study is trying to determine using NEPCM with steady source with the approach used. The conclusion is that more nanoparticles increase the heat flux between the SAW device but also reduce the time before the phase change is complete; therefore, the heat starts increasing again. These are important conclusions.

As shown by increase of time, the volume fraction of the system is decreased till all the material inside the volume is changed to liquid. As the volume fraction of nanoparticle material is increased, the heat transfer rate increases, and the phase change process is faster since the solid NEPCM phase change is finished sooner, and there would be no time delay after that. 


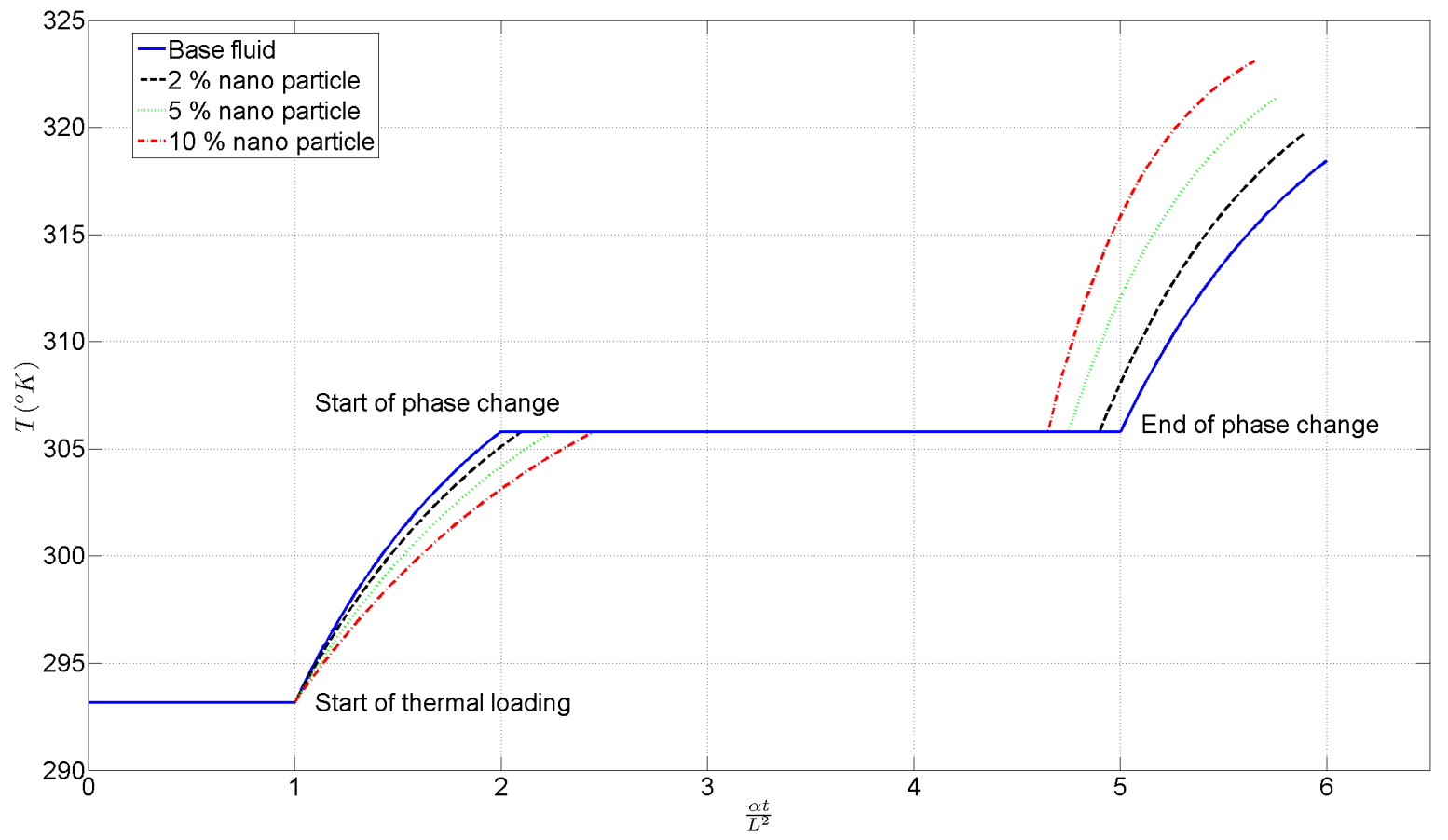

Figure 12. Time dependency of maximum temperature.

\section{Conclusions}

The present study was focused on the change in cooling capacity of a SAW system in case of high frequency heating with adding a phase change material. We wanted to investigate the effect of adding nanoparticles on fluid movement on cooling performance as it potentially provides two key advantages: increasing convective heat exchange at the electric boundary, as well as inside the fluid. Melting of NEPCMs inside a rectangular cavity next to the SAW cell was used for cooling purposes. Free convection heat transfer of a NEPCMs in an square cavity was modeled throughout the mass, momentum, and energy governing equations solved by using the finite element method. The results also show that the NEPCM causes heat transfer improvement up to $10 \%$. The advantage of the current study is the increase of heat transfer, where the disadvantage of the devised solution compared to other methods from the scientific literature is preparing the NEPCM and its cost.

Funding: This research received no external funding.

Institutional Review Board Statement: Not applicable.

Informed Consent Statement: Not applicable.

Data Availability Statement: The data presented in this study are available on request from the corresponding author.

Conflicts of Interest: The authors declare no conflict of interest.

\section{Nomenclature}

$\begin{array}{ll}\mathrm{C} & \text { Constant pressure specific heat }\left(\mathrm{J} \cdot \mathrm{kg}^{-1} \cdot \mathrm{K}^{-1}\right) \\ \mathrm{g} & \text { Gravity constant }\left(\mathrm{m} \cdot \mathrm{s}^{-2}\right) \\ \mathrm{l} & \text { Length of the cavity } \\ \mathrm{H} & \text { Height of the cavity } \\ H_{s f} & \text { latent heat of melting }\left(\mathrm{J} \cdot \mathrm{kg}^{-1}\right) \\ \mathrm{k} & \text { Coefficient of the thermal conductivity }\left(\mathrm{W} \cdot \mathrm{m}^{-1} \cdot \mathrm{K}^{-1}\right)\end{array}$




$\begin{array}{ll}\mathrm{Nu} & \text { Nusselt number } \\ \mathrm{p} & \text { pressure }(\mathrm{Pa}) \\ \mathrm{Pr} & \text { Prandtl number } \\ \mathrm{Ra} & \text { Rayleigh number } \\ \mathrm{Ste} & \text { Stefan number } \\ \mathrm{T} & \text { temperature }(\mathrm{K}) \\ \mathrm{u} & x \text {-velocity component }\left(\mathrm{m} \cdot \mathrm{s}^{-1}\right) \\ \mathrm{v} & y \text {-velocity component }\left(\mathrm{m} \cdot \mathrm{s}^{-1}\right) \\ \mathrm{x} & x \text {-Cartesian coordinate }(\mathrm{m}) \\ \mathrm{y} & y \text {-Cartesian coordinate }(\mathrm{m}) \\ \mathrm{Greek} \mathrm{symbols} & \\ \mu & \text { Dynamic viscosity }\left(\mathrm{kg} \cdot \mathrm{s}^{-1} \mathrm{~m}^{-1}\right) \\ \alpha & \text { Coefficient of thermal diffusivity }\left(\mathrm{m}^{2} \cdot \mathrm{s}^{-1}\right) \\ \beta & \text { Coefficient of thermal expansion }\left(\mathrm{K}^{-1}\right) \\ \phi & \text { Weight ratio of the nanoparticle inside NEPCM } \\ \rho & \text { Density }\left(\mathrm{kg} \cdot \mathrm{m}^{-3}\right) \\ \text { Subscript } & \\ \mathrm{b} & \text { Bulk properties } \\ \mathrm{c} & \text { cold surface } \\ \mathrm{f} & \text { base fluid } \\ \mathrm{h} & \text { Hot surface }\end{array}$

\section{References}

1. Wang, Y.; Tao, X.; Tao, R.; Zhou, J.; Fu, Y.Q. Acoustofluidics along inclined surfaces based on AlN/Si Rayleigh surface acoustic waves. Sens. Actuators Phys. 2020, 306, 111967.

2. Kong, D.; Nishio, K.; Kurosawa, M.K. Surface acoustic wave propulsion system with acoustic radiation force. Sens. Actuators Phys. 2020, 309, 111943. [CrossRef]

3. Dryburgh, P.; Smith, R.J.; Marrow, P.; Lainé, S.J.; Li, W. Determining the crystallographic orientation of hexagonal crystal structure materials with surface acoustic wave velocity measurements. Ultrasonics 2020, 108, 106171. [CrossRef] [PubMed]

4. Jiang, T.; Li, C.; Han, Q. Surface acoustic waves in 2D-phononic crystal of laminated pillars on a semi-infinite ZnO substrate. Phys. Lett. A 2019, 383, 125956. [CrossRef]

5. Alagoz, S.; Apak, Y. Removal of spoiling materials from solar panel surfaces by applying surface acoustic waves. J. Clean. Prod. 2020, 253, 119992. [CrossRef]

6. Weser, R.; Winkler, A.; Weihnacht, M.; Menzel, S.; Schmidt, H. The complexity of surface acoustic wave fields used for microfluidic applications. Ultrasonics 2020, 106, 106160. [CrossRef] [PubMed]

7. Liang, X.; Lin, B.; Liu, Z. Analysis of velocity calculation methods of laser-induced surface acoustic wave. Ultrasonics 2020, 100, 105985. [CrossRef]

8. Zhang, Y.; Cai, Y.; Zhou, J.; Xie, Y.; Liu, S. Surface acoustic wave-based ultraviolet photodetectors: A review. Sci. Bull. 2020, 65, 587-600. [CrossRef]

9. Chan, J.S.; Poh, P.E.; Ismadi, M.-P.; Yeo, L.Y.; Tan, M.K. Enhancing greywater treatment via MHz-Order surface acoustic waves. Water Res. 2020, 169, 115187. [CrossRef]

10. Hsu, J.-C.; Lin, Y.-D. Microparticle concentration and separation inside a droplet using phononic-crystal scattered standing surface acoustic waves. Sens. Actuators A Phys. 2019, 300, 111651. [CrossRef]

11. Zhang, H.; Xu, X.-D.; Cheng, L.-P.; Zhang, S.-Y. Experimental studies of a new type of non-contact rotary motors driven by surface acoustic waves. Sens. Actuators A Phys. 2019, 297, 111524. [CrossRef]

12. Wang, Y.; Chen, D.; Wu, C.; Xie, J. Effect of droplet boundary behaviors on SAW attenuation for potential microfluidic applications Jpn. J. Appl. Phys. 2019, 58, 037001. [CrossRef]

13. Li, G.-C.; Yang, P.; Zhang, W.; Wu, Z.; Kou, Z.-H. Enhanced film cooling performance of a row of cylindrical holes embedded in the saw tooth slot. Int. J. Heat Mass Transf. 2019, 132, 1137-1151. [CrossRef]

14. Lamanna, L.; Rizzi, F.; Bhethanabotla, V.R.; De Vittori, M. Conformable surface acoustic wave biosensor for E-coli fabricated on PEN plastic film. Biosens. Bioelectron. 2020, 163, 112164. [CrossRef] [PubMed]

15. Qin, F.; Li, B.; Chen, L.; Shang, Z. Laser-induced surface acoustic waves for measurement of elastic constants based on mode conversion. Mater. Chem. Phys. 2020, 242, 122523. [CrossRef]

16. Aslam, M.Z.; Jeoti, V.; Karuppanan, S.; Pandian, M.S.; Suresh, K. Surface acoustic wave modes characteristics of CMOS compatible $\mathrm{SiO} 2 / \mathrm{AlN} / \mathrm{SiO} 2 / \mathrm{Si}$ multilayer structure with embedded electrodes. Sens. Actuators A Phys. 2020, 313, 112202. [CrossRef]

17. Jamalabadi, M.Y.A.; Park, J.H. Investigation of Property Variations on Freezing of PCM Containing Nanoparticles. World Appl. Sci. J. 2014, 32, 672-677. 
18. Jamalabadi, M.Y.A.; Park, J.H. Effects of Brownian motion on freezing of PCM containing nanoparticles. Therm. Sci. 2016, 20, 1533-1541.

19. Jamalabadi, M.Y.A. Rational Design Calculation of Surface Acoustic Wave Gas Sensor. Phys. J. 2020, 6, $62-87$.

20. Jamalabadi, M.Y.A. MD Simulation of Brownian Motion of Buckminsterfullerene Trapping in nano-Optical Tweezers. Int. J. Opt. Appl. 2015, 5, 161-167.

21. Mohammad, A.J.; Mohammad, S.; Abdullah, A.; Truong, N.; Enio, B.F. Entropy Generation in Thermal Radiative Loading of Structures with Distinct Heaters. Entropy 2017, 19, 506. 